\begin{tabular}{|c|c|}
\hline Title & Pursuing the Sociological Study of Environmental Governance in Japan: A n Introduction to the Special Issue \\
\hline Author(s) & Miyauchi, Taisuke \\
\hline Citation & $\begin{array}{l}\text { International Journal of Japanese Sociology, 15(1), 2-6 } \\
\text { https://doi.org/10.1111/.1475-6781.2006.00081.x }\end{array}$ \\
\hline Issue Date & $2006-11$ \\
\hline Doc URL & http:/hdl.handle.net/2115/50978 \\
\hline Rights & $\begin{array}{l}\text { A uthor Posting. } \odot \text { The A uthors 2006. This is the author's version of the work. It is posted here for personal use, not for } \\
\text { redistribution. The definitive version was published in International journal of Japanese sociology, volume15, number1, } \\
\text { pages 2-6. http://dx.doi.org/10.1111/.1475-6781.2006.00081.x }\end{array}$ \\
\hline Type & article \\
\hline File Information & IJJS15-1_2.pdf \\
\hline
\end{tabular}

Instructions for use 


\section{Pursuing the Sociological Study of Environmental Governance in Japan: An Introduction to the Special Issue}

Taisuke Miyauchi

Japanese environmental sociology has developed rapidly over the last two decades and has made a significant contribution in the greater Japanese environmental context. This progress, however, has not been adequately conveyed in the English language. This special issue, focusing on environmental governance in Japan, tries to show readers how Japanese sociologists are now tackling environmental problems and to introduce the unique frameworks they have constructed as well.

By way of introduction, I will offer a brief history of Japanese environmental sociology and then outline its features with reference to the articles in this issue.

Japanese environmental sociology began with the sociological study of 'kogai' or industrial pollution issues. Nobuko Iijima, a pioneer of this relatively new discipline, studied the world-renowned Minamata Disease (see Harutoshi Funabashi's and Reiko Seki's articles herein) in the 1960s. Minamata Disease, which first broke out in Minamata in 1956 and then in Niigata in 1965, was and remains a tragic environmental disaster caused by the Methyl mercury discharged by factories. Thousands of people have suffered. Iijima conducted social research on the pollution victims and found a socially-formed complex of suffering, in which they suffer not only from disease but also from poverty, social discrimination, the collapse of their families and so on. Disease and social distress were not only related, but served to mutually accelerate one another (Iijima, 1984; 1992).

Minamata Disease, in Minamata and again in Niigata, attracted the attention of numerous social scientists. Masazumi Harada, a doctor long involved with the Minamata Disease, has recently advocated Minamata Studies which approach the Minamata Disease through a variety of disciplines. Many social scientists think that Minamata was the starting point for environmental sociology. However, Japanese environmental sociology had other roots as well in the study of social movements and in rural sociology. The sociology of social movements began in the 1960s, when 'jumin undo' (local residents' movements) formed to counter environmentally-destructive development. While some fought against air pollution, others, mainly fishermen, struggled against marine pollution. These movements differed from conventional social movements such as workers' movements. To some sociologists, these movements appeared to present a new social paradigm, or a post-modern paradigm, to counter modernization or economy-oriented development. These sociologists also think the movements represent an alternative type of social integration or an alternative political process. Thus they studied how the movements first came into being, how they organized their activities and what they appealed, and how they tried to find a new social system. Then, in the 1980s, another type of movement arose, where citizens tried to create or rebuild a sustainable environment as in the case of recycling and forest conservation activities. These new movements often sought collaboration with the 
government. Sociologists, again, were interested in these activities as an indication of a new social formation.

Social movements arose not only in 'environmentally conscious' urban areas but also, and often, in rural and 'conservative' areas. Some sociologists studying these rural movements discovered elements derived from community-based logic. Rural people proved to be against destructive development, not from an ecological perspective, but based upon social norms, the social structure and social change in rural areas. This finding led sociologists to use and elaborate the frameworks of rural sociology when analyzing environmental issues.

This new current of studies led to the formation of an academic guild, the Japanese Association for the Environmental Sociology, in 1992. The group quickly acquired many, mostly young, sociologists and has been the source of a wide range of studies since.

The above-mentioned history of Japanese environmental sociology has yielded the following: First, environmental sociology seeks to study the social structures of environmental issues. For environmental issues, this structure covers a variety of subjects. What kind of social factors produce an environmental issue? What kind of institutional mechanisms and political processes retard the solution? What kind of social values contribute to the fact that an environmental issue may be socially focused and solved immediately?

Environmental sociology also studies environmental movements and policy. It focuses on the social aspects of issues, movements and policy. It studies the community, norms, values, livelihoods, institutions, social structures, gender, social stratification and so on.

Funabashi (1992) presents the theory of "the benefit zone and victimized zone." This theory is based upon the discovery that, for many environmental problems, there is a separation of those areas or people who benefit and those who are victimized. For example, a bullet train project benefits urban train users while causing suffering among residents along the rail line. Funabashi also points out that this separation of the two zones may offset the finding of a solution or even worsen the problem. Funabashi (1998) also seeks environmental control systems, wherein, he argues, the enhancement of public discussion arenas is essential.

Environmental sociology also attempts to address the ecological structures in human life, which do not appear as environmental 'issues'. It seeks to study environmental systems not in nature itself, but in human-nature and in human-human relations.

For example, some argue the relation of community institutions to water sustainability. Toward the use of water in a sustainable manner, local communities establish rules and create organizations. Some factors such as social stratification may destroy these rules resulting in a deterioration in the sustainability of the water supply.

Japanese environmental sociology has also made an effort to advocate policies based on structural analysis. A typical example is Koichi Hasegawa's unique proposal to construct a 'green fund' for wind power energy, a proposal which has had a major influence on movements (Hasegawa, 2004).

Second, Japanese environmental sociology emphasizes the people's perspective. When we talk 
about an environmental problem, we should deliberately think about whom the problem effects, and the extent to which it really is a 'problem'. Even if the problem does really exist, it may exist only for particular social groups, and not for others. Or, an environmental problem may have a different meaning for different actors. For example, garbage may be a financial problem for the local government, an ecological problem for ecologists, and a city planning problem for some residents.

In this regard, Japanese environmental sociology mainly seeks to understand the perspective of ordinary people or of the socially weak. The Minamata experience, again, has contributed to this attitude. Minamata showed that 'neutral' science tended to neglect the brutal nature of the victims' situation and to exacerbate the situation. Medical scientists stayed within the framework of their discipline and thereby failed to provide solutions to the victims, and often further distressed them. Thus, the Minamata experience taught sociologists to focus on the weak.

In this relation, the commons theory is one of the main focuses of Japanese environmental sociology. The commons are the often informal institutions where local residents own, use or manage the immediate or surrounding environment, such as forests, rivers and the sea.

Both traditional and new commons systems are studied here. The commons theory (Miyauchi, 2001; Inoue and Miyauchi eds., 2001) addresses people's long-term involvement with the environment. Even though rivers, forests and the sea are not legally owned by the local people, sociologists acknowledge and even advocate their collective rights to nature and the land as socially substantial rights. Having accumulated empirical studies on the commons, sociologists argue that the common property institutions or rules are the key to the local governance of sustainability.

Related to the commons studies, Yukiko Kada's article herein presents 'life-environmentalism' through an analysis of Japanese river policy. 'Life-environmentalism', an influential framework in Japanese environmental sociology, highlights the relation of local people to nature in their daily lives, and studies their perspective. This approach gives weight to the sustainability of livelihood, rather than to scientifically ecological sustainability.

Not surprisingly, people's attitudes toward nature are neither consistent nor uniform and life-environmentalism underscores these inconsistencies. Yasushi Maruyama's article, studying issues related to pest monkey in northern Japan, reveals the perception of 'various monkeys'. He shows that local people may have a variety of perspectives and that one person may even have varying perspectives with regard to the monkeys. Monkeys are sometimes harmful and disgusting, while at other times they are pathetic. On the other hand, the policy regarding pest monkeys, based mainly on science and from outside of the community, simplifies the issue and does not account for the locally diversified relations to monkeys. This inevitably leads to a failure in the policy.

Hideo Nakazawa's article also shows the failure of a local government. Kamakura City, seeking advanced environmental policy by way of a top-down approach, failed in terms of legitimacy. Nakazawa argues that the local government's policy, based on the slogan 'Think globally, act locally', was unsuccessful in reaching the people's reality, where they recognized traffic congestion and the building of condominiums as important environmental problems. The local government did not 
recognize this and failed to include these issues in their 'advanced' environmental policy.

Third, the above-mentioned features of Japanese environmental sociology have been based on field research in a wide range of social/spatial fields: rural/urban areas, organizations/individuals, movements/everyday lives. Empirical methodology, mainly based on this fieldwork, is crucial to the discipline. A number of case studies have been conducted in a wide variety of areas and fields. These include: conflicts at World Heritage sites, struggles where nuclear power plants have been planned, conflicts between dam construction projects and local residents, community-based recycling activities, movements and policy for historical buildings, changes in an irrigation system and community; and so on. Empirical methods include: interview research, participant observation, ethnomethodology, life history studies, structure analysis, historical analysis and the use of surveys and questionnaires. Although some environmental sociologists pursue mass data analysis, most adhere to field research. This emphasis on the people's perspective leads to a focus on locality, both in theory and methodology. Many scholars seek, through empirical and profound research into local issues, the postulation of a viable theory. Furthermore, some scholars advocate participatory or action research in which researchers participate as one of the main actors in an effort to solve the problem. In such cases 'issues' in environmental sociology include issues that have been identified by the sociologist.

The focal point of environmental sociology in Japan today is the dynamism of governance. Based on the above features and methodology, it would appear that we should avoid the naive discussion of governance. In place of statements like "we need environmental governance," or "the government and volunteer groups should collaborate," environmental sociology should address the reality and the very dynamism of governance, especially at a local level.

Funabashi's article looks back at the Minamata Disease in Kumamoto to find those factors which are crucial to environmental governance: an effective juridical system, the public sphere, the quality of individuals, sensitivity of the society in the discovery of a problem, autonomy of the research, the organization of movements, and compensation design.

Meanwhile, Seki's article addresses the Minamata Disease in Niigata and emphasizes the autonomy of the victims' movements. She points out that the victims' own participatory action in the health survey contributes to governance and to the solution.

Participatory research is now emphasized for various environmental issues. Participatory research of a local region, or Jimotogaku, began with Minamata in the 1990s and has spread throughout Japan since. A number of local areas are now involved in action research regarding the local environment and landscape, seeking community-based sustainable development.

Nakazawa's article argues that agri-environment movements reflect a new Japanese environmental governance. In the case of the City of Kamakura, in the face of the failure of the local government's "Think global" approach, citizens' farming activities have succeeded and have taken the initiative in environmental conservation. Nakazawa stresses the local nature of this new movement.

We are now facing a wide range of environmental problems and issues and Japanese environmental sociology has tried to give them constructive frameworks. The articles in this special 
issue present not only Japanese environmental sociology but Japanese approaches to environmental governance as well.

\section{References}

Funabashi, Harutoshi, 1992, "Environmental Problems in Postwar Japanese Society", International Journal of Japanese Sociology, 1:3-17.

Funabashi, Harutoshi, 1998, "Kankyo Mondai no Mirai to Shakai Hendo (The Future of Environmental Problems and Social Change)" in Harutoshi Funabashi and Nobuko Iijima eds., Kankyo: Koza Shakaigaku 12 (Environment: The Series of Sociology 12), Tokyo: University of Tokyo Press, pp.191-224.

Hasegawa, Koichi, 2004, Constructing Civil Society in Japan: Voices of Environmental Movements, Melbourne: Trans Pacific Press.

Iijima, Nobuko, 1984, Kankyo mondai to higaisha undo (Environmental problems and the Victim's Anti-pollution Movement), Tokyo: Gakubunsha.

Iijima, Nobuko, 1992, "Social Structures of Pollution Victims", Jun Ui ed, Industrial Pollution in Japan, Tokyo: United Nations University Press, pp.154-172.

Inoue, Makoto and Taisuke Miyauchi eds., 2001, Siriizu Kankyo Shakaigaku 2 Komonzu no Shakaigaku (Series Environmental Sociology 2 The Sociology of the Commons) , Tokyo: Shinyosha.

Miyauchi, 2001, "Komonzu no shakaigaku: Shizen Kankyo no Shoyu, Riyo, Kanri wo Megutte (The Sociology of the Commons: On Ownership, Use and the Management of Nature)", in Hiroyuki Torigoe ed., Koza Kankyo Shakaigaku 3 Shizen kankyo to Kankyo Bunka (Environmental Sociology 3 Nature and Environmental Culture), Tokyo: Yuhikaku, pp.25-46. 